BULLETIN Bulletin hispanique

HISPANIQUE Université Michel de Montaigne Bordeaux

123-2 | 2021

Investigaciones semánticas y léxicas actuales

\title{
Lope de Vega, Barlaán y Josafat. Daniele Crivellari (ed.)
}

Madrid: Cátedra, 2021

María Ángeles González Luque

\section{(2) OpenEdition}

Journals

Edición electrónica

URL: https://journals.openedition.org/bulletinhispanique/14532

DOI: 10.4000/bulletinhispanique.14532

ISBN: 1775-3821

ISSN: 1775-3821

\section{Editor}

Presses universitaires de Bordeaux

\section{Edición impresa}

Fecha de publicación: 20 diciembre 2021

Paginación: 374-379

ISBN: 979-10-300-0-745-9

ISSN: 0007-4640

\section{Referencia electrónica}

María Ángeles González Luque, «Lope de Vega, Barlaán y Josafat. Daniele Crivellari (ed.)», Bulletin hispanique [En línea], 123-2 | 2021, Publicado el 20 diciembre 2021, consultado el 06 febrero 2022. URL: http://journals.openedition.org/bulletinhispanique/14532 ; DOI: https://doi.org/10.4000/ bulletinhispanique.14532

Este documento fue generado automáticamente el 6 febrero 2022.

Tous droits réservés 


\section{Lope de Vega, Barlaán y Josafat. Daniele Crivellari (ed.)}

Madrid: Cátedra, 2021

María Ángeles González Luque

\section{REFERENCIA}

Lope de Vega, Barlaán y Josafat, ed. de Daniele Crivellari. - Madrid: Cátedra, 2021, 358 pp. ISBN: 978-84-376-4208-6.

1 Llega a las manos de los admiradores del Fénix la reciente edición de Barlaán y Josafat al cuidado del profesor Daniele Crivellari (Università degli Studi di Salerno), quien ha centrado su carrera investigadora en el estudio y edición de varios autores del Siglo de Oro (Lope de Vega, Vélez de Guevara, Tirso de Molina, Antonio de Solís y el doctor Juan Pérez de Montalbán, entre otros muchos) y ha estudiado diferentes temáticas y géneros de la literatura aurisecular (presencia y evolución de los romances en el teatro, recepción del drama barroco en el siglo XX, examen de las comedias de privanza, etc.). Entre sus principales trabajos cabe destacar, en primer lugar, su monografía Marcas autoriales de segmentación en las comedias autógrafas de Lope de Vega: estudio y análisis (Reichenberger, 2013), donde Crivellari realizó un fino análisis de los signos paratextuales de los testimonios escritos de puño y letra del dramaturgo con la finalidad de interpretar el modo en que Lope segmentaba, distribuía y disponía los textos dramáticos; tal estudio sin duda ha sido fundamental para ahondar en el conocimiento de la comedia hagiográfica que aquí reseñamos. Actualmente Crivellari es investigador del grupo PROLOPE, cuyo principal objetivo es, como es de sobra conocido, emprender la edición crítica de la obra dramática de Lope de Vega, lo que ha revolucionado el panorama de estudios lopescos en estos decenios.

2 Tras el descubrimiento del autógrafo de Barlaán y Josafat por parte de Crivellari en 2014, ahora ve la luz una rigurosa edición crítica, acompañada de un minucioso estudio introductorio de la obra. Entre las ediciones modernas que se han presentado de esta 
obra dramática, la realizada por José Fernández Montesinos en 1935 ha sido el referente al que la crítica y el lector contemporáneo han acudido para su consulta. Pese a que el editor realizó una buena labor filológica y se eligió como texto base para la edición el testimonio autógrafo de Lope -supuestamente perdido en 1940 tras sufrir un incendio la biblioteca privada en la que se conservaba (Holland House, Londres, Inglaterra)-, la actual edición Crivellari viene a suplir la carencia del bagaje histórico y crítico que presentaba el trabajo ecdótico de Montesinos, ya que el avance del conocimiento en el patrimonio literario lopesco planteado en las últimas décadas le ha permitido a Crivellari una mayor comprensión de la obra tanto como producto literario como texto en la vertiente historiográfica del autor. Además, la consulta directa del autógrafo le ha brindado a Crivellari la posibilidad de estudiar y analizar con mayor detalle el proceso de composición de la comedia, ya que este tipo de testimonio ofrece una versión fidedigna de la obra y facilita la observación de los aspectos materiales y paratextuales del texto.

El estudio introductorio que antecede a la edición del texto (págs. 9-146) comienza con un planteamiento sobre el estado de la cuestión del estudio de la comedia hagiográfica de Lope, donde, frente al pleno desconocimiento de la materia a principios del siglo XX, se resalta en la actualidad «un crecimiento constante y [...] un número considerable [de] trabajos que abordan el tema a partir de perspectivas muy distintas» No obstante, Crivellari considera que «no significa esto que la tarea investigadora sobre el asunto pueda considerarse concluida» (pág. 12). Con relación a Barlaán y Josafat, Crivellari describe brevemente el origen y la trayectoria de esta leyenda, sobre la que apunta como fuente documental para su composición La historia de los dos soldados de Cristo, Barlaán y Josafat (1608), de Juan de Arce Solórzeno. Asimismo, expone la razón (el proceso de reflexión religiosa en la que se encontraba el autor) por la que predominan tanto en su producción dramática como en la lírica los temas religiosos (págs. 17-18).

En el apartado «San Buda, venido de Oriente: "Barlaán y Josafat" y la comedia hagiográfica» (págs. 18-37), Crivellari expone un notable análisis sobre los elementos de la obra que la adscriben a la comedia de santos y aquellas particularidades que la alejan del patrón de este género, lo que le ha permitido «llegar a una visión de conjunto sobre el texto [...] y poner de relieve aquellos aspectos que [...] hacen de Barlaán y Josafat una pieza digna de interés» (pág. 19). Por un lado, el editor se apoya en los estudios realizados por la crítica sobre los cambios realizados por Lope con respecto a la fuente original. En este sentido, dada la importancia del dramaturgo en adaptar el texto dramático al gusto del público, Crivellari se detiene en explicar cómo el autor construyó una pieza en la que se prescinde de todas las partes absolutamente doctrinales de su fuente para centrarse principalmente en la espectacularidad por medio de los motivos temáticos propios del género (págs. 20-24).

Entre los elementos con los que Lope quiso superar los límites de la comedia hagiográfica, por otro lado, el editor especifica la caracterización particular que le otorgó el Fénix a sus personajes, ya que «con Barlaán y Josafat Lope busca una materia nueva, una fábula nunca vista ni oída, en los escenarios al menos» (pág. 25). Asimismo, frente a la falta de cohesión estructural de las comedias hagiográficas, Crivellari destaca la unidad de la trama de Barlaán y Josafat a partir del tema del conflicto, planteado desde tres perspectivas: general, personal y sentimental (pág. 26). Sobre el carácter secundario de Leucipe planteado por la crítica, Crivellari arroja luz sobre la presencia de este personaje en la obra, en tanto que su papel no solamente es seductor, 
sino que comparte una serie de rasgos vivenciales (el cautiverio) con el protagonista (pág. 27). Como cierre de este apartado, Crivellari trata sobre el análisis de las técnicas empleadas por Lope para la construcción de la obra drámática, especialmente en lo que se refiere a la conexión entre los conceptos de palabra y representación, por una parte, y entre narración y descubrimiento de la realidad, por otra parte, a partir de la descripción detallada de una selección de microsecuencias del relato (págs. 28-37).

El descubrimiento del paradero del autógrafo de Barlaán y Josafat (1611) es una de las grandes aportaciones de Crivellari a la historia de la transmisión textual y de su análisis de esta comedia hagiográfica. En el correspondiente apartado de la introducción (págs. 28-59), se exponen los resultados de ese acercamiento filológico al autógrafo de Lope, que repercute notablemente en la comprensión del proceso de composición del texto, el usus scribendi de Lope, el trabajo de las compañías de actores sobre la obra y aquellos aspectos que dan cuenta de la representación de la comedia en las tablas. En este sentido, el editor ha analizado exhaustivamente el manuscrito autógrafo con el objetivo de conocer, de un lado, las fases de escritura y la revisión de la obra por el autor, y la intervención de manos ajenas en el texto, de otro lado. Sobre la naturaleza del autógrafo lopesco, Crivellari confirma que se trata de una copia en limpio, elaborada a partir de un borrador, tras un análisis de los errores del testimonio y su tipología, así como de las intervenciones realizadas por el dramaturgo para mejorar el texto y calificadas por el editor como «estilísticas» (págs. 40-53). Con respecto a este asunto, cabría preguntarse si este tipo de errores (haplo- y duplografía, saltos por homoiotéleuton, etcétera) son propios del borrador y posteriormente heredados en la versión limpia o son errores surgidos en el propio acto de copia, puesto que, como bien es sabido en el campo de la ecdótica, todo acto de copia conlleva la transmisión de errores de la versión precedente y/o la creación de los mismos en el nuevo testimonio. La relevancia de este estudio se fundamenta en la eficacia de Crivellari en reconocer dentro del autógrafo las marcas realizadas por Lope consciente o inconscientemente, que respondían a la manera en que el autor estructuraba el texto dramático. De este modo, resulta sugerente apreciar la implicación del editor en esta lectura atenta del autógrafo, pues ha sabido reconocer aquellos aspectos que no estaban pensados o destinados para el lector, sino dirigidos al autor. Con relación a las intervenciones de la compañía presentes en el texto (añadidos, correcciones u omisión de fragmentos prescindibles), se destaca su importancia por ser decisivas para la adecuada representación de la comedia en las tablas de los corrales barrocos (págs. 55-59).

7 En el tercer apartado de la introducción, titulado «Avatares de la comedia entre reelaboraciones, huellas y representaciones» (págs. 59-71), Crivellari se detiene en presentar y describir el testimonio impreso de esta comedia en la XXIV parte (1641), con relación a sus particularidades textuales y paratextuales. Para ello, comparte con el lector las cuestiones que le surgieron cuando se acercó filológicamente a este texto: la paternidad de la obra y las razones que llevaron a esa mano ajena al autor a la reelaboración de la pieza dramática (pág. 60). Con respecto al primer punto, resulta de interés el debate sobre la autoría de este testimonio diferente al autógrafo, pues es de gran complejidad establecer si fue Lope o un autor de comedias quien realizó esta labor de reedición, dada la falta de materiales y herramientas que permitan aclarar este entramado. Pese al análisis expuesto, el propio editor reconoce «no obtener unos datos concluyentes que permitan descartar con seguridad absoluta que Lope pudiera decidir reelaborar en algún momento su propio texto, por las razones que fueran, por otros varios elementos sugieren, en cambio, que probablemente fuera otra persona la que 
emprendió este proceso de reescritura» (pág. 66). No obstante, apuesta por la futura localización de nuevos documentos y el empleo del análisis estilométrico y de la ortoepía como mecanismos que permitan dar una respuesta a este interrogante autorial (pág. 67). Asimismo, otro de los debates que se han planteado en torno a Barlaán y Josafat es su posible influencia en la Vida es sueño calderoniana. Frente a las posturas contrapuestas de la crítica que apoyan por la existencia de esta relación o su ausencia, la aportación de Crivellari esclarece esta polémica comparativa de las piezas dramáticas, subrayando la pervivencia de la leyenda de los dos santos en el teatro español de los siglos XVII y XVIII gracias al gusto del público por este tema (págs. 68-71).

8 A continuación, el editor dedica un espacio al apartado «Descripción de los testimonios e historia textual» (págs. 71-80). Tras la presentación del panorama textual de la obra, ofrece, de un lado, una información detallada y minuciosa sobre los testimonios en los que se ha basado para su edición crítica. Posteriormente, de otro lado, plantea la transmisión textual de la pieza dramática en época moderna, con una breve alusión al texto base empleado para las respectivas ediciones y el tratamiento otorgado por los editores a este material. Además, expone los resultados obtenidos tras el análisis de los testimonios antiguos y el trabajo de collatio, ofreciendo la descripción del stemma codicum.

Junto con el descubrimiento del autógrafo, otra aportación importante de Crivellari al estudio de los testimonios autógrafos del Fénix y a la edición de su obra dramática es el análisis de la pieza teatral a partir de la segmentación (págs. 80-119). Primeramente, ofrece un resumen de las diversas formas métricas que componen Barlaán y Josafat, con atención a sus tipologías, las cantidades numéricas y los porcentajes en cada acto y en total (págs. 80-83). Además, presenta una tabla donde expone las particularidades del tercer acto transmitido por los testimonios diferentes al autógrafo (págs. 84-85). En base a esta información métrica de carácter cuantitavo, expone un resumen de la trama argumental de la pieza según el resultado de la segmentación del texto, dividido en cuadros y microsecuencias (págs. 85-101), sobre las que aporta unas notables consideraciones acerca de la estructura de la comedia (págs. 101-104). En este estudio de la segmentación de la obra cabe señalar el análisis de la disposición y la funcionalidad de las distintas tipologías de líneas marcadas por el dramaturgo en el texto (págs. 105-113). Los resultados alcanzados le han permitido "poner de relieve no solo los elementos estructurales y estructurantes de la misma, sino también los ejes fundamentales en los que descansaba la pieza, tanto desde un punto de vista temático como a nivel de la acción dramática» (pág. 113). La aportación del análisis de la segmentación por parte de Crivellari en el estudio y la edición de la obra lopesca repercute en la recuperación del texto dramático desde el plano espectacular y proporciona una útil información para la interpretación y el análisis de los textos del Fénix. Por esta razón, sería también conveniente y provechoso emplear y aplicar el estudio de la segmentación en la edición crítica de las obras dramáticas lopescas en las que se conserven los autógrafos.

10 Con relación al apartado «Esta edición» (pág. 119-123), Crivellari presenta los criterios establecidos para la fijación del texto, basados en la modernización ortográfica y el respeto a las particularidades fonético-fonológicas de la lengua española del Siglo de Oro. Se enriquece notablemente la edición con el empleo del aparato positivo de variantes, que viene acompañado de un subapartado sobre las características del 
autógrafo de Lope (págs. 351-358). Cabe destacar también la anotación del texto por ser exhaustiva y completa, lo que enriquece la calidad y la interpretación de la obra. Asimismo, en el «Apéndice», se puede encontrar el tercer acto del testimonio impreso para una lectura completa de la comedia hagiográfica (págs. 287-329).

11 La actual edición crítica de Barlaán y Josafat es una buena muestra del gran avance que se ha producido en los estudios filológicos, especialmente, en lo referente al conocimiento de la figura del Fénix y su obra literaria. La publicación de una edición de esta calidad y complejidad ha supuesto una labor relevante en el campo de la ecdótica. La recuperación del testimonio autógrafo implica una notable contribución en el legado del patrimonio literario del dramaturgo. Junto con ello, el estudio de la segmentación de la obra puede significar una especial aportación en la edición de textos dramáticos, ya que permitiría conocer cómo concibió Lope la composición de su obra a nivel espectacular. En definitiva, Crivellari, conocedor del teatro del Siglo de Oro, ha sabido emplear y difundir los instrumentos necesarios para llevar a cabo la realización de esta edición crítica con un magistral rigor filológico. La calidad de su trabajo es fruto de la pasión que ha mostrado Crivellari, no solamente con la figura del Lope, sino con la Filología, pues su edición ha cumplido sobradamente con la finalidad de la ecdótica: recuperar la palabra primigenia y difundir el patrimonio literario.

\section{AUTORES}

MARÍA ÁNGELES GONZÁLEZ LUQUE

Universidad de Jaén 